\title{
Vania Bambirra y la alternativa insurreccional a inicios de los años $70^{*}$
}

\section{Vania Bambirra and insurrectional alternative to the early $70 \mathrm{~s}$}

\begin{abstract}
Resumen
Este artículo tiene como objetivo analizar el trabajo desarrollado por la intelectual brasileña Vania Bambirra, quien propuso en sus trabajos asociados al Centro de Estudios Socioeconómicos de la Universidad de Chile (CESO) un análisis sobre la dependencia latinoamericana y la necesidad de liberación del continente, planteando la urgencia de construir organizaciones político-militares capaces de llevar adelante los procesos revolucionarios, haciendo una crítica a la estrategia político-militar de la teoría del foco, definiendo como capitalismo dependiente la situación latinoamericana y proponiendo a la insurrección como la estrategia para el triunfo de la revolución socialista.
\end{abstract}

Palabras clave: insurrección, socialismo, teoría del foco, izquierda revolucionaria.

\begin{abstract}
This article aims to analyze the work done by Brazilian intellectual Vania Bambirra, who proposed to its partners the Center for Social and Economic Studies at the University of Chile (CESO ) an analysis of Latin American dependence and the need for liberation of the continent jobs, raising the urgency to build military-political able to carry forward the revolutionary processes, making a critique of the politicalmilitary strategy theory focus, defined as dependent capitalism Latin American situation and proposing to insurrection as the strategy for the triumph of the organizations socialist revolution.
\end{abstract}

Keywords: insurrection, socialism, theory of focus, revolutionary left.

\footnotetext{
* Este trabajo es una investigación personal cuya base es la ponencia titulada "La insurrección armada como alternativa al proyecto socialista en Chile y Latinoamérica. Los aportes de la intelectual Vania Bambirra en la década de los 60 y principios de los años 70"

${ }^{* *}$ Chilena. Licenciada en Historia de la Universidad de Santiago de Chile, Magíster @ e en Historia mención Historia de Chile en la misma universidad. Integrante de Eclosión. Centro de acción y reflexión histórica. Contacto lbricenoramirez@gmail.com
} 


\section{Introducción}

La década del cincuenta y sesenta fue un período fructífero en el desarrollo del pensamiento latinoamericano, ideas como subdesarrollo, dependencia, liberación y revolución conformaron el marco teórico de un vasto grupo de intelectuales cuyo objetivo era encontrar respuestas al subdesarrollo del continente e idear estrategias políticoeconómicas que permitieran hacer frente a la crisis del desarrollismo. La producción de estas ideas fue posible por la existencia de condiciones académicas que facilitaron tal situación. En Santiago de Chile desde fines de la década del cincuenta hasta 1973 convergieron numerosos intelectuales latinoamericanos en centros de estudios como FLACSO, CEPAL, ILPES, CESO y CEREN transformándose la capital en el punto neurálgico de los debates en torno a las condiciones latinoamericanas. Una de sus principales preocupaciones fue la posición de América Latina en el capitalismo mundial, cuestión que se profundizó a partir del triunfo de la Revolución Cubana en 1959. Bajo este contexto, los intelectuales, especialmente aquellos ligados a la izquierda latinoamericana adquirieron un papel relevante como observadores de la realidad y creadores de propuestas alternativas al capitalismo.

Una de las características de los intelectuales de izquierda de este período fue la adscripción declarada a ideologías, partidos políticos y organizaciones revolucionarias ${ }^{1}$, que en conjunto con su trabajo en los centros de estudios les permitió producir y difundir sus ideas más allá de los espacios tradicionales académicos, relacionándose con esferas políticas como colaboradores o críticos ${ }^{2}$. Michael Löwy indica como ejemplo de ello a intelectuales como André Gunder Frank, Ruy Mauro Marini, Aníbal Quijano y Luis Vitale quienes no se limitaron sólo al campo académico, también se integraron a las luchas del movimiento popular siendo parte de lo que denominó izquierda revolucionaria ${ }^{3}$. Estamos hablando de intelectuales comprometidos y militantes, cuestión que dio un nuevo carácter a su trabajo y a su relación con el movimiento popular y las organizaciones revolucionarias.

La Revolución Cubana contribuyó a la conformación de un pensamiento marxista latinoamericano revolucionario, en donde los intelectuales comenzaron a debatir no sólo por las condiciones de América Latina en términos sociales y económicos, sino también por la viabilidad de repetir esa experiencia en el continente. Löwy señala que en el período que estamos indagando surgieron "corrientes radicales cuyos puntos de referencia comunes son la naturaleza socialista de la revolución y la necesidad de la lucha armada"4.

La opción por la lucha armada de la izquierda revolucionaria manifestó el peso gravitante de la experiencia cubana y las lecciones político-estratégicas que de ella se desprendieron. Estas indagaciones decantaron en algunos casos en análisis y propuestas que establecían la necesidad de masificar el proceso cubano, argumentando que la revolución

\footnotetext{
${ }^{1}$ Lozoya, Ivette. "Pensar la revolución: pensamiento latinoamericano e intelectuales en el MIR chileno 19651973. Propuesta teórica y metodológica para su estudio desde la historia intelectual y la historia de la violencia”. Revista Humanidades. № 27 (Enero-Junio 2013). Pág. 181. http://revistahumanidades.unab.cl/wpcontent/uploads/2013/07/A8.-LOZOYA.pdf

${ }^{2}$ Lozoya, Ivette. Op. Cit. Pág. 185.

${ }^{3}$ Löwy, Michael. El marxismo en América Latina. Editorial Era. México, 1980. Pág. 53

${ }^{4}$ Löwy, Michael. Op. Cit. Pág. 11.
} 
socialista sería el camino indicado para superar el subdesarrollo y dependencia del continente. Estas ideas fueron especialmente desarrolladas por los intelectuales ligados a la Teoría de la Dependencia entre quienes se encontraba la intelectual brasileña Vania Bambirra. La intelectual propuso en sus trabajos asociados al Centro de Estudios Socioeconómicos de la Universidad de Chile (CESO) un análisis sobre la dependencia latinoamericana y la necesidad de liberación del continente, planteando la urgencia de construir organizaciones político-militares capaces de llevar adelante los procesos revolucionarios, haciendo una crítica a la estrategia político-militar de la teoría del foco, definiendo como capitalismo dependiente la situación latinoamericana y proponiendo a la insurrección como la estrategia para el triunfo de la revolución socialista.

Este artículo tiene como finalidad analizar el imaginario político de la intelectual Vania Bambirra a través del examen de dos trabajos publicados por el CESO Diez años de insurrección en América Latina (1971) y La Revolución Cubana: una reinterpretación (1973) y un artículo publicado en la revista Monthly Review "Los errores de la teoría del foco: Análisis crítico de la obra de Régis Debray" (1967). El enfoque de esta investigación es descriptivo-interpretativo, ya que por una parte nos interesa dar a conocer el trabajo de la intelectual, poco conocido en nuestro país y por otra parte, buscamos construir un acercamiento interpretativo del imaginario político de la intelectual y sus aportes a la teoría revolucionaria de los años setenta, estudiando su interpretación de la Revolución Cubana, el análisis de las causas para el desarrollo del proyecto socialista y la instalación de éste en América Latina, sus ideas respecto de la estrategia insurreccionalista y los cuestionamientos que realizó a la Teoría del Foco.

Se plantea como hipótesis que el imaginario político de la intelectual es el reflejo de una interpretación de la realidad latinoamericana que le permitió la construcción de un discurso en que fijó al proletariado como la clase revolucionaria, posicionó a la organización partidaria como vanguardia y estableció que dicha vanguardia debía tener una estructura político-militar, asumiendo la necesidad de implementar la lucha armada como estrategia bajo objetivos políticos y sustento teórico. Creemos que estos elementos nutrieron el pensamiento marxista latinoamericano, aportando a la conformación de una cultura política revolucionaria ${ }^{5}$, la cual desarrolló una teoría y praxis en que la lucha por el socialismo era una lucha política e insurreccionalista.

Para llevar a cabo esta investigación es necesario definir qué entenderemos por imaginario político y cómo esta categoría nos permitirá indagar en el pensamiento de la intelectual. Imaginario es una categoría que ha sido trabajada por diversas disciplinas, entre ellas la historia, psicología y antropología y su desarrollo ha tenido como objetivo establecer la relación entre la dimensión simbólica que un individuo, colectividad o

\footnotetext{
${ }^{5}$ Entendemos por cultura política el estilo de hacer política que construye una organización y las formas en que pone en práctica dicho estilo, donde confluyen las experiencias individuales con los objetivos colectivos que se fijan los integrantes de ésta, conformando una identidad colectiva partidaria. En este sentido, la cultura política tiene relación con las intersubjetividades de la estructura partidaria, enmarcada en una realidad social y contexto histórico determinado y que se expresa en prácticas políticas, para este caso, una práctica revolucionaria. Briceño, Laura. "Subversivos y Alegres". Los jóvenes militantes del MAPU-Lautaro". Revista Divergencia. $\quad \mathrm{N}^{\circ}$ 2, año 1, julio-diciembre 2012. Pág. $11-12 . \quad$ En: http://www.revistadivergencia.cl/docs/ediciones/02/01_subversivos_y_alegres.pdf
} 
sociedad hace de su realidad. Desde el estudio de las mentalidades la categoría de imaginario se situó en el campo de las representaciones colectivas o individuales, en palabras de la historiadora Evelyn Patlagean "el campo de lo imaginario está constituido por el conjunto de representaciones que desbordan el límite trazado por los testimonios de la experiencia y los encadenamientos deductivos que estos autorizan. Lo que significa que cada cultura, y por tanto cada sociedad e incluso cada nivel de la sociedad compleja tiene su imaginario"6. La historiadora, siguiendo a Jacques Le Goff, sitúa lo imaginario en la experiencia humana y como un elemento que constituye la vida social.

La representación opera como una acción que permite al sujeto o a un conjunto de ellos traducir su realidad y transformarla en una nueva idea, es decir, se le reconoce a este acto una acción creadora ${ }^{7}$. Ante ello, el imaginario se compone de la experiencia humana y la representación entrega como resultado una forma de ver y crear realidad en la que subyacen motivaciones, sistemas de valores y símbolos que la representan. En esta lógica, el filósofo y psicoanalista Cornelius Castoriadis propone que lo imaginario es "algo inventado, donde se manifiesta un deslizamiento o desplazamiento de sentido, en el que unos símbolos ya disponibles están investidos con otras significaciones que las suyas «normales» o canónicas" ${ }^{8}$. La clave, de acuerdo a este autor, es comprender que lo imaginario es una constitución activa ${ }^{9}$, ya que imaginar algo nuevo no responde a un descubrimiento, sino a un constante proceso de creación.

Jaime Massardo establece en la revisión del imaginario político de Luis Emilio Recabarren que en su construcción hubo un "proceso de apropiación de la realidad, de conocimiento del mundo; substrato cultural estrechamente ligado a la sensibilidad que origina la experiencia de la vida social, actuando a la vez como su prolongación y como la forma más propiamente humana de expresión de ésta" ${ }^{\text {". }}$. Massardo visualiza el imaginario político como un proceso de creación que se nutre de la experiencia social y constituye un modo de ver la realidad que hace actuar de una determinada manera al sujeto que está imaginando políticamente. En esta perspectiva, para Massardo imaginario político es el "el proceso de formación de una determinada constelación de intuiciones, de percepciones y de representaciones de la vida política, por una colección de imágenes que, en función de su valor simbólico, organizan la visión de la vida social y el propio discurso" ". El autor enfatiza en la conexión de la construcción del imaginario político con la vida social lo que da cuenta de una categoría capaz de manifestar no sólo una representación de la realidad,

\footnotetext{
6 Plantgean, Evelyn. "La historia de lo imaginario". En: Le Goff. Et. Al. La nueva historia. Editorial Mensajero, Bilbao, 1988. Pág. 249.

7 Belinsky, Jorge. “Aproximación indirecta: Lo imaginario en la perspectiva de Jacques Le Goff”. En: Belinsky, Jorge. Lo imaginario: un estudio. Editorial Nueva Visión Argentina, Buenos Aires, 2007.

${ }^{8}$ Castoriadis, Cornelius. La institución imaginaria de la sociedad. Vol. 1. Marxismo y teoría revolucionaria. Turquest Editores, Barcelona, 1983. Pág. 219-220.

${ }^{9}$ Castoriadis, Cornelius. Op. Cit. Pág. 231.

${ }^{10}$ Massardo, Jaime. La formación del imaginario político de Luis Emilio Recabarren. Contribución al estudio crítico de la cultura política de las clases subalternas de la sociedad chilena. Editorial LOM. Santiago, 2008. Pág. 29.

11 Ídem.
} 
sino también el vínculo existente entre quien imagina y su contexto, tanto social como histórico.

Con ello, el imaginario político se sitúa en el nivel de las representaciones de la realidad, pero lo que lo distancia de una interpretación es su capacidad creadora y proyectora, ya que no se trata sólo de un diagnostico sino de proyectar los caminos posibles de transformación. Esta dimensión es recogida Ernesto Laclau quien define imaginario como "un conjunto de significaciones, discursos y representaciones que saturan el hiato resultante del choque entre lo real y lo simbólico. Este registro imaginario, según veremos, es el que totaliza el campo de una cierta experiencia y le da su peculiar dimensión de horizonte" $" 12$. Laclau reúne en su definición elementos, al igual que los autores anteriores, que parecen ser claves para comprender la categoría de imaginario político, la relación entre lo imaginado y la experiencia social, y la dimensión de horizonte. Estos elementos dinamizan la categoría y la sitúan en el espacio social, en donde es posible observar la relación del autor de dicho imaginario político con su entorno y contexto.

En tal sentido, imaginario político expresa una realidad pensada que se nutre por los procesos de recepción, apropiación y producción de las ideas en un contexto determinado. A su vez, permite una lectura que se enfoca en el pensamiento desarrollado por un sujeto o colectividad enlazado a la comprensión de los elementos que permitieron la construcción de ese imaginario. Así, imaginario político se aprecia como un conjunto de ideas que tienen como fin construir una nueva realidad a partir de la experiencia con el medio social y contexto en el que está inserto, siendo una interpretación de la realidad que se expresa a través del discurso, creador de realidades en cuanto define horizontes posibles y propone una institucionalización para que dichas ideas se concreten en la realidad.

Lo anterior visualiza el estrecho vínculo entre quien imagina y su entorno social e histórico, en un proceso, siguiendo a Horacio Tarcus, que incluye la recepción, apropiación, producción y difusión de las ideas ${ }^{13}$. Esto manifiesta el dinamismo del imaginario político como corpus de ideas que se entrelaza con el pasado, el presente y el futuro que se imagina, y da cuenta de un proceso de construcción que involucra ideas que se nutren de concepciones de la realidad para transformarse en un nuevo conjunto de ideas posibles de extender por el medio social. Por ello, el análisis del imaginario político de la intelectual Vania Bambirra implica situar la construcción de su pensamiento en el contexto intelectual y político y, a su vez, analizar las ideas que contribuyeron a la conformación de su imaginario y cómo estas fueron parte del marxismo latinoamericano en la década de los

\footnotetext{
${ }^{12}$ Laclau, Ernesto. "Populismo y transformación del imaginario político en América Latina". En: Boletín de Estudios Latinoamericanos y del Caribe No. 42 (Junio de 1987). Pág. 27. En: https://www.jstor.org/stable/25675327

${ }^{13}$ Horacio Tarcus propone que el examen de la construcción de un pensamiento determinado se expresa en un conjunto de momentos que representan un proceso en que uno o más autores recepcionan, producen, difunden y se apropian de ideas, creando una constelación de pensamientos. Para el caso particular de este artículo, el trabajo de la intelectual brasileña se ubica en la recepción y apropiación de ideas y percepciones históricas revolucionarias, que le permiten construir, a través de la interpretación, su imaginario político que contribuye a la red de pensamiento marxista latinoamericano de los años sesenta. Tarcus, Horacio. "La historia intelectual y la problemática de la recepción”. Introducción del libro Marx en la Argentina. Sus primeros lectores obreros, intelectuales y científicos (1871-1910). Editorial Siglo XXI. Buenos Aires, 2007. http://shial.colmex.mx/textos/Tarcus-6.pdf
} 
setenta. Por lo tanto, la estrategia metodológica apunta a examinar los textos escogidos considerando contex to de enunciación, recepción de las ideas que circularon en el período en la que escribió, la producción intelectual y la proyección de sus ideas en el marco de la configuración de un marxismo latinoamericano marcado por la Revolución Cubana.

\section{Insurrección como estrategia para la lucha por el socialismo}

Vania Bambirra fue una cientista política brasileña graduada de la Universidad Federal de Minas Gerais, militante en los años sesenta de la Organización Revolucionaria Marxista-Política Obrera (POLOP) en Brasil. En su exilio en Chile tras el golpe de Estado al gobierno de João Goulart en 1964 se vinculó al Centro de Estudios Socio Económicos de la Universidad de Chile (CESO) integrando el equipo de investigación sobre las relaciones de dependencia en América Latina bajo la dirección de Theotonio Dos Santos, el objetivo de dicho equipo era crear una teoría marxista de la dependencia que superara las teorías desarrollistas. Bambirra manifestó en su libro El Capitalismo dependiente latinoamericano que este equipo buscaba comprender el carácter y las contradicciones del capitalismo dependiente en su fase de integración monopólica mundial y, al mismo tiempo pretendía entregar elementos para la reorientación de la concepción estratégico-táctica que guiaba a los movimientos revolucionarios, ya que, a juicio de la intelectual, estos habían sufrido duros reveses por sus equivocados supuestos programáticos ${ }^{14}$.

En sus trabajos estableció que el imperialismo no era un fenómeno externo al capitalismo latinoamericano, sino más bien un elemento constitutivo, por esta razón los países latinoamericanos eran incapaces de un desarrollo nacional independiente. Sostuvo que esta situación decantó en la década del sesenta en el agotamiento del modelo desarrollista, el desgaste de las relaciones populistas y de la alianza clasista de los partidos comunistas latinoamericanos, generándose un distanciamiento entre las clases dominantes y el movimiento popular que comenzaba a elevar sus demandas,

Latinoamérica ha vivido en la década del 50 un período de expansión y de crecimiento económico, como consecuencia de la expansión general del sistema capitalista mundial en su nueva fase de integración monopólica internacional, impulsada por la empresa multinacional que empieza a surgir a partir de la postguerra (...) a partir del 60 ese desarrollo empieza a agotarse. No obstante, el movimiento popular sigue en expansión y se pone, cada vez más, en el orden del día la necesidad de cambiar el carácter de la lucha popular, o sea, sobrepasar los niveles reformistas y reivindicativos en los cuales ha estado sumergida y elevarla a un nivel

\footnotetext{
${ }^{14}$ Vania Bambirra entendió la Dependencia como "una categoría analítico-explicativa", que le permitió caracterizar la realidad latinoamericana como "una situación en la cual un cierto grupo de países tiene su economía condicionada por el desarrollo y expansión de otra economía a la cual está sometida. Una situación que condiciona los límites y posibilidades de acción y comportamiento de los hombres, condicionando una estructura interna que la redefine en función de las posibilidades estructurales de las distintas economías nacionales". Nota previa VII. El capitalismo dependiente... Op. Cit. Pág. 7-8.
} 
superior de cuestionamiento del sistema en su conjunto. Es decir, empiezan a plantearse y a llevarse a efecto los primeros intentos insurreccionales. ${ }^{15}$.

La crisis del desarrollismo y la Revolución Cubana propiciaron la conformación de un pensamiento marxista latinoamericano revolucionario ${ }^{16}$ que veía en la revolución socialista las posibilidades de transformación estructural necesarias para hacer frente a la dependencia capitalista y el subdesarrollo. Estas ideas serían seguidas no sólo por intelectuales y organizaciones de izquierda, sino también por el movimiento popular, el que confluía en la idea del socialismo como una alternativa al capitalismo.

Justamente por eso ella [la Revolución Cubana] significó el término de la etapa del nacionalismo populista, en la medida en que -por un lado- su triunfo se da cuando está culminando el proceso de monopolización, concentración y centralización del poder económico, en el sistema capitalista dependiente de América Latina, cuando son liquidadas las posibilidades de un desarrollo autónomo del capitalismo en los países dependientes, y -por otro lado- ella demuestra que la superación de la dependencia, del atraso y de los límites al desarrollo, sólo es posible cuando se supera el propio sistema económico-social, es decir, el capitalismo ${ }^{17}$.

Bambirra en el análisis de la realidad latinoamericana consignó que existían las condiciones objetivas que hacían posible en la década de los sesenta la lucha por el socialismo a través de movimientos insurreccionales. No obstante, fue clara y enfática en su trabajo Diez años de insurrección en América Latina, editado por el CESO, que estas condiciones no habían alcanzado la madurez necesaria para que la ola revolucionaria lograra el triunfo, señalando que la década del sesenta era un período de transición hacia el socialismo, el que se alcanzaría en la década siguiente. Esta apreciación se situó en las transformaciones que el pensamiento marxista estaba viviendo; en 1956 en el XX Congreso del Partido Comunista de la URSS se aprobó la tesis de la "determinación de un tránsito pacífico al socialismo (...) o más bien, tránsito institucional al socialismo"18, que rechazaba a la lucha armada como estrategia político-militar. Sin embargo, tres años más tarde, la Revolución Cubana (1959) y sus estrategias guerrilleras tensionaron dicha tesis en el comunismo latinoamericano, planteando la vía armada como estrategia.

Bambirra criticó la visión pacífica-institucional comunista principalmente por la posición aliancista de los partidos comunistas latinoamericanos -extensión de la experiencia de los Frentes Populares-, su vinculación con las burguesías y el carácter reformista de su política. Advirtió que tanto el imperialismo norteamericano y las burguesías nacionales dificultarían el triunfo de la revolución en el continente poniendo como ejemplo el golpe de Estado en Brasil en 1964, hecho que marcó el descenso del

\footnotetext{
${ }^{15}$ Bambirra, Vania. Diez años de insurrección en América Latina. Tomo I. Ediciones prensa Latinoamericana S.A. Chile. Santiago, 1971. Pág. 30.

${ }^{16}$ Löwy, Michael. El marxismo en América Latina... Op.cit. Pág. 48.

${ }^{17}$ Bambirra, Vania. Diez años de insurrección... Op. Cit. Pág. 36.

18 Gallardo, Helio. "Revolución”. En: Salas, Ricardo. Et. Al. Pensamiento Crítico Latinoamericano. Conceptos fundamentales. Ediciones Universidad Católica Silva Henríquez. Santiago, 2005. Pág. 921
} 
movimiento insurreccionalista-popular y puso de manifiesto la resistencia ante nuevas experiencias como la cubana. Así, por un lado, propuso que las organizaciones revolucionarias debían romper la alianza de clases con la burguesía y estrechar lazos con el movimiento popular, y por otro lado, construir una política-estratégica insurreccional que quebrara la idea reformista-pacífica que proponía la URSS,

De esta forma fueron las condiciones objetivas en que se encontraba la situación política y económica de América Latina, las que condujeron a la necesidad de superar los viejos esquemas, produciéndose así un vacío político e ideológico que crea las condiciones para el florecimiento de un pensamiento y de una acción revolucionaria e insurreccional. Como veremos más adelante, aunque ésta no logró superar completamente el nacionalismo populista, representaba una etapa de transición - expresada en el foquismo- que creaba las bases para un periodo cualitativamente diferente, al que sólo logrará entrar definitivamente a fines de la presente década, y que anuncia para los años 70 una época de profunda y generalizada revolución social $^{19}$

La intelectual planteó que había inmadurez en las organizaciones insurreccionales de la primera mitad de la década del sesenta al asumir la tarea revolucionaria, esto la llevó a manifestar la necesidad de que las organizaciones estuvieran dotadas de una estructura política-militar. Así, el imaginario político de la intelectual recepcionaba la idea de que la superación del nacionalismo-populista y del reformismo debía ser por medio del insurreccionalismo, lo que iniciaría la nueva fase de ascenso del movimiento popular en América Latina. En ese sentido planteó,

La táctica reformista contemporánea que consistió en hacer avanzar las conquistas populares dentro de los marcos de la democracia burguesa y buscar "consolidar y asegurar" todas las concesiones otorgadas por la burguesía -sean las que correspondían a las necesidades del desarrollo del régimen burgués, o las que éste concedía por presión el movimiento popular- no podría sino conducir a la mantención del capitalismo dependiente y a dificultar el desarrollo de los procesos de insurrección popular ${ }^{20}$.

En definitiva, rechazó la idea de la revolución etapista, pacífica, democrática y nacional, visión que había prevalecido en los partidos comunistas latinoamericanos, sosteniendo que tales ideas no permitirían superar el capitalismo dependiente. De acuerdo con ello, luego de analizar la realidad latinoamericana en la década del sesenta, -la influencia de la Revolución Cubana, la emergencia de las organizaciones revolucionarias y la presión social y política del movimiento popular-, consideró que,

Fueron gestándose y madurando las condiciones para el desarrollo de una nueva izquierda, inspirada en la victoria de la Revolución Cubana que puso en el orden del día la táctica del enfrentamiento armado como la única vía para la toma del poder, y

\footnotetext{
${ }^{19}$ Bambirra, Vania. Diez años de insurrección... Op. Cit. Pág. 37.

${ }^{20}$ Bambirra, Vania. Diez años de insurrección... Op. Cit. Pág. 49.
} 
por el conflicto chino-soviético, que representó un quiebre en la continuidad del revisionismo en el plano mundial. Esta nueva izquierda se oponía a la táctica reformista de la mayoría de los $\mathrm{PC}$, rompiendo por lo tanto el monopolio de la crítica de la izquierda que durante muchos años ejercieron en forma equivocada los trotskistas y ofreciendo nuevas alternativas teóricas y prácticas para la conducción de la revolución ${ }^{21}$.

Como señaló Michael Löwy, la Revolución Cubana permitió el renacimiento de un marxismo latinoamericano y su emancipación del marxismo-leninismo vinculado a la URSS $^{22}$. Bambirra aportó a esta nuevo marxismo un análisis de la realidad de América Latina desde la Teoría de la Dependencia y su imperiosa necesidad de liberación por medio de la configuración de una izquierda revolucionaria, en un contexto marcado por la "movilización articulada de diversos sectores sociales que, desde su dolor social y sus utopías y procedimientos de resistencia y luchas populares, se organizan y orientan hacia la transformación radical de las situaciones de injusticia, discriminación, opresión y muerte"23. Así, un amplio conjunto social -militantes, intelectuales, sujetos populares- se unieron en el ideal revolucionario, adquiriendo el ideario marxista latinoamericano un carácter de liberación, que para la intelectual brasileña se tradujo en la liberación de la dependencia capitalista.

En su propuesta insurreccionalista Bambirra definió a la izquierda revolucionaria latinoamericana a partir de tres tipos de organizaciones - pro-chinas, foquistas y nueva izquierda ${ }^{24}$, conectadas con la revolución a nivel internacional y continental, las que se diferenciaban en la visión del sujeto revolucionario, el espacio de la lucha y sus estrategias. A partir de esta definición, la intelectual señaló que las organizaciones foquistas fueron las que tuvieron mayor expresión en los años sesenta en América Latina,

Porque representaba la concepción teórica-práctica con mayor coherencia interna independientemente de las justas y fundamentales críticas que pueden hacérselessea porque ofrecía una camino aparentemente más fácil al resolver toda una

\footnotetext{
${ }^{21}$ Bambirra, Vania. Diez años de insurrección... Op. Cit. Pág. 52.

${ }^{22}$ Löwy, Michael. El marxismo en... Op.cit. Pág. 53.

${ }^{23}$ Gallardo, Helio. Op. Cit. pág. 923.

${ }^{24}$ A juicio de la intelectual, las organizaciones pro-chinas, foquistas y nueva izquierda, se diferenciaban en la estrategia revolucionaria. Las pro-chinas planteaban que el carácter de la lucha en América Latina debía ser de liberación nacional, antiimperialista, antifeudal y democrática, centrándose en el campesinado como sujeto revolucionario. Las organizaciones foquistas, se centraban en la inmediatez de la insurrección ya que las condiciones objetivas ya estaban en Latinoamérica y la lucha insurreccional desencadenaría las condiciones subjetivas a través de la creación del foco guerrillero. El campesinado era la clase fundamental y concebían la lucha como antiimperialista, anticapitalista y antifeudal, subestimaban la importancia del partido como vanguardia, del proletariado urbano y de las ciudades. La nueva izquierda, se planteó en oposición de la visión reformista de los PCs, planteaban la necesidad de convertirse en vanguardias revolucionarias para preparar la lucha insurreccional. Concebían la revolución como socialista y antiimperialista, conducida por una alianza obrera-campesina bajo el liderazgo de la clase obrera. En oposición a las organizaciones foquistas no creían en la inmediatez de la lucha insurreccional, sino en la formación de cuadros políticos, la importancia otorgada a la lucha política y en la generación de una estrategia revolucionaria adecuada al continente. Bambirra, Vania. Diez años de insurrección... Op. Cit. Pág. 55-58.
} 
compleja problemática desencadenando la lucha insurreccional basada más en el valor de los combatientes que en la fuerza social del movimiento revolucionario, sea por contar con el fuerte respaldo del ejemplo de cambio histórico provocado por la revolución cubana ${ }^{25}$.

El foquismo derivado de la experiencia cubana se nutrió del pensamiento castrista, el que se caracterizaba por el voluntarismo revolucionario y la orientación militarista. La expansión de este tipo de organizaciones por el continente se consolidó en La Habana en el marco del Congreso de la Organización Latinoamericana de Solidaridad (OLAS) en 1967 donde se definió la "guerra de guerrillas como el método más eficaz para la lucha en la mayoría de los países del continente"26, esto explica la influencia del foquismo en las organizaciones revolucionarias en la segunda mitad de la década del sesenta y la masificación de la lucha armada como estrategia.

$\mathrm{Si}$ bien la intelectual brasileña entendió al foquismo como una estrategia insurreccional, planteó las dificultades que veía en éste tanto en su accionar como en lo teórico, principalmente por su vocación insurreccionalista inmediata y la consideración de que el foco desencadenaría la lucha revolucionaria. El análisis y crítica que publicó Bambirra a la teoría foquista de Régis Debray, en diciembre 1967, dos meses después de la muerte del Che en Bolivia, nos permite suponer que su crítica no se produjo como consecuencia del fracaso de la guerrilla en Bolivia y por la muerte de Guevara, sino como un trabajo de análisis y discrepancia en cuanto al trabajo teórico y práctico que proponía el foquismo en América Latina.

\section{Crítica al foquismo y al trabajo del intelectual de Régis Debray.}

Dentro de la intelectualidad izquierdista no sólo se debatió en torno al socialismo y sus proyecciones, sino también por las formas estratégicas que debían seguirse. Este panorama propició la creación de la Teoría del Foco desarrollada por Régis Debray, la que estaba basada en la guerra de guerrillas empleada en la Revolución Cubana (1959), en el Congo (1965) y Bolivia (1967), estas dos últimas experiencias lideradas por Ernesto Che Guevara. Régis Debray planteó en la idea foquista: "Lo más pequeño es el foco guerrillero, núcleo del ejército popular, y no es un frente el que crea ese núcleo, sino que es el núcleo el que, al desarrollarse, permitirá crear un frente nacional revolucionario. Un frente se hace en torno de algo existente, no solamente en torno de un programa de liberación. Es el "pequeño motor" que pone en marcha el "gran motor" de las masas y precipita la formación de un frente, en la ascensión de las victorias obtenidas por el pequeño motor" ${ }^{27}$. El foco, centrado en la acción y estrategia militar dejaba en manos del ejército popular el avance revolucionario, lo que implicaba que la guerrilla cumplía el papel de generar los objetivos revolucionarios y precipitaría la formación de un frente nacional. El partido y la

\footnotetext{
${ }^{25}$ Bambirra, Vania. Diez años de insurrección... Op. Cit. Pág. 55.

${ }^{26}$ Löwy, Michael. El marxismo en... Op. Cit. Pág. 50.

${ }^{27}$ Debray, Régis. “¿Revolución en la Revolución?” Cuadernos Casa de las Américas, № 1. Cuba, 1967. En: Revista Lucha Armada. Año1, No 1. Buenos Aires, 2005. Pág. 141.
} 
participación de las masas populares urbanas debían sumarse al avance del foco, lo político se subordinaba a lo militar.

Para criticar la teoría foquista y particularmente el trabajo de Régis Debray, Vania Bambirra escribió "Los errores de la teoría del foco: análisis crítico de la obra de Régis Debray”, artículo que publicó en la revista Monthly Review el año 1967 bajo el seudónimo de Cléa Silva ${ }^{28}$. Esta crítica la hizo basándose en tres artículos del autor: “¿Revolución en la Revolución?", "El castrismo: la gran marcha de América Latina" y "América Latina: Algunos problemas de estrategia revolucionaria".

Vania Bambirra estableció siete errores cometidos por Debray a la hora de plantear el foquismo como la teoría revolucionaria para América Latina. Señaló que el intelectual hizo un deficiente análisis socio-económico de la realidad latinoamericana, donde el principal error estaba en creer que en América Latina regía un sistema feudal. Consignó que Debray no hizo un análisis de las clases sociales y no definió el papel del proletariado ni de la ideología proletaria. Con su visión centrada en el foco, subordinó el partido a la guerrilla, lo político a lo militar, sin fundamentación teórica. Contrapuso el campo a la ciudad, mitificando al campesinado, subestimando a la clase obrera y su capacidad de vanguardia. Propuso que Debray despreció la experiencia histórica del movimiento revolucionario mundial, considerando a la Revolución Cubana como única experiencia posible de repetir en el continente. Y por último cayó en el culto a la espontaneidad. Frente a ello, la intelectual sostuvo que Debray tuvo problemas teóricos y de interpretación al hacer el análisis de la realidad latinoamericana, ya que su trabajo careció de un examen sistémico del carácter de la Revolución Cubana y de las clases fundamentales en el continente $^{29}$ perdiendo sustento teórico y validez práctica, principalmente porque desconoció al proletariado como sujeto revolucionario y su experiencia histórica de movilización. En consecuencia, planteaba Bambirra, Debray descartó de su análisis las características sociales y económicas del continente, extrapolando la experiencia cubana a la definición de la estrategia insurreccional revolucionaria en América Latina. En respuesta a Debray, Vania Bambirra estableció,

La clase fundamental es el proletariado (industrial y agrícola) que, en su alianza con otros sectores del proletariado y de la pequeña burguesía radicalizada, podrá movilizar vastos sectores sociales, como los marginales, intelectualidad, los profesionales liberales y los estudiantes ${ }^{30}$.

Observando el error de Debray al caracterizar a la sociedad latinoamericana como campesina-feudal, Vania Bambirra criticó la falta de sistematización del análisis del intelectual francés, planteando que uno de los principales requisitos del análisis marxista es examinar el carácter de la revolución y de las clases fundamentales de esa revolución ${ }^{31}$.

\footnotetext{
${ }^{28}$ Desconocemos las razones que llevaron a Vania Bambirra a utilizar el seudónimo de Cléa Silva en su artículo en la Revista Monthly Review.

${ }^{29}$ Bambirra, Vania. "Los errores de la teoría del foco: Análisis crítico de la obra de Régis Debray". En: Monthly Review. Selecciones en castellano, Santiago, Nº. 45, diciembre de 1967. Pág. 38.

${ }^{30}$ Ibíd.

${ }^{31}$ Bambirra, Vania. "Los errores de la teoría del foco... Op. Cit. Pág. 39.
} 
Debray indicó: "un análisis rápido del capitalismo latinoamericano permite ver cómo está orgánicamente ligado a las relaciones de producción feudal en el campo"32, justificó este argumento planteando que el desarrollo de la burguesía latinoamericana estuvo ligada a la producción agrario-exportadora, poniendo como ejemplo los casos de Brasil y Colombia. Si bien el desarrollo agrario y el campesinado representaban un importante porcentaje respecto de la composición social y económica de América Latina, Debray desconoció la importancia del desarrollo del proletariado a lo largo de la historia del siglo XX en el continente, obviando la movilización y constitución de la clase obrera y su participación como sujeto social y actor político.

A juicio de Bambirra, Debray no consideró lo que el propio Marx señaló en relación al desarrollo del capitalismo: "el capital empieza sometiendo a su imperio al trabajo en las condiciones técnicas históricas en que lo encuentra" ${ }^{33}$. Esto quiere decir que en América Latina, desde su inserción en la economía mundial, con la conquista de los españoles y el desarrollo de una economía de patrón de acumulación, el capital se fue adaptando a las relaciones de producción existente y las fue modificando a medida que se fue ampliando su inserción en el sistema capitalista. Por lo tanto, América Latina no vivió un proceso feudal, sino un capitalismo colonial $^{34}$, adquiriendo un carácter dependiente. Para Bambirra era necesario aclarar este error porque sí América Latina estaba regida por un sistema feudal la lucha por la liberación tendría un carácter distinto al que se estaba desarrollando, es decir, no sería una revolución socialista. En este sentido, el imaginario político de la intelectual se constituyó por el análisis social y económico de la realidad latinoamericana siguiendo los lineamientos de la Teoría de la Dependencia y el marxismo, lo que la hizo plantear que para la superación del capitalismo dependiente el camino era la revolución socialista, definiendo al proletariado (campesino y obrero) como la clase revolucionaria.

A juicio de Bambirra, el error del análisis de las clases sociales de Debray en América Latina, se le une el hecho de subordinar lo político a lo militar, estableciendo a la guerrilla como el foco revolucionario capaz de crear un frente nacional. Esta idea de Debray surgió del supuesto básico que "el revolucionario se forma en la misma lucha", tesis defendida por Fidel Castro, base del castrismo y pilar de la teoría foquista. Bambirra planteó que,

La guerra, como único factor unificador no debe ser tomada como dogma. Lo que realmente unifica no es la guerra, sino sus objetivos, la capacidad de una vanguardia para servir de centro coordinador, precisando para eso antes tener la claridad de visión, o sea, capacidad de analizar claramente el proceso histórico, demostrando en

\footnotetext{
${ }^{32}$ Debray, Régis. "El castrismo: la gran marcha de América Latina”. En: Suplemento a la edición $N^{\circ} 30$ Revista Punto Final. Primera quincena, junio 1967. Pág. 23.

${ }^{33}$ Marx, Carl. El Capital. Editorial Fondo de Cultura Económica. México. Pág. 248. En: Bambirra, Vania. Los errores de la teoría del foco... Op. Cit. Pág. 39.

${ }^{34}$ Al respecto, Enrique Dussel consignó que Sergio Bagú, en 1949, postulaba que la economía colonial no fue feudal, sino un capitalismo colonial, por lo que Iberoamérica nació para integrar el ciclo de capitalismo naciente. El último Marx (1863-1882) y la liberación latinoamericana: un comentario a la tercera y a la cuarta redacción de "El capital". Editorial Siglo XXI. México D.F., 1990. Pág. 285.
} 
la práctica de la lucha diaria, en todos los sectores fundamentales, que es una fuerza organizada, disciplinada, coherente; en suma, que es un partido ${ }^{35}$

La crítica de Bambirra a Debray en este punto es la no consideración del partido dentro del proceso revolucionario cubano, ya que el intelectual francés no consideró el accionar del Movimiento 26 de Julio. El partido ocupó un lugar central en el trabajo de Bambirra, entendiéndolo como la organización que debía liderar el proceso revolucionario en América Latina, proponiendo que lo militar era parte integrante de la estrategia de una organización partidaria,

Todo indica que cualquier movimiento armado que se inicie en América Latina, deberá enfrentar, en un primer momento, no solamente la represión nacional sino al propio imperialismo que tratará de liquidar la revolución. Sólo un movimiento muy bien organizado y con una fuerte base de sustentación urbana (tanto desde el punto de vista militar, logístico, como desde el punto de vista político) podrá progresar y triunfar. Esto quiere decir que ahora, aún más que en los años anteriores, la experiencia cubana no se repetirá ${ }^{36}$

En contraposición a Debray y las ideas foquistas, Bambirra defendió la idea de que lo militar se sostenía por un conjunto de objetivos y estrategias políticas guiadas por una organización político-militar. Entendió y manifestó la urgencia de organizar la lucha armada bajo el parámetro de una organización partidaria que motivara el accionar insurreccional en el movimiento popular, consignando la necesidad de forjar una vanguardia política y militar para enfrentar la resistencia del imperialismo norteamericano y las burguesías nacionales. De acuerdo con ello, planteó que la revolución y la instalación del socialismo eran una lucha política en que el proletariado debía combatir por el poder y control estatal a la burguesía, con una estrategia militar que en conjunto con un programa y objetivos políticos se posicionaran como organizaciones con capacidad de enfrentamiento y posibilidades reales de triunfo,

Para iniciar el enfrentamiento directo con la represión, o sea, iniciar la insurrección armada, es necesario tener previamente un mínimo de organización funcionando bajo los moldes partidarios. Puede que no sea aún completamente un partido, puedo no tener siquiera ese nombre, pero de cualquier forma no basta solamente un heroísmo semejante al de Granma. Aún en los países en que la industria no sea el factor económico fundamental y que por tanto, el proletariado no tenga un peso considerable en la vida política, la formación del partido es indispensable para encauzar la lucha revolucionaria. Si en esos casos el partido no se justifica en cambio, ampliamente, desde un punto de vista operacional, instrumental ${ }^{37}$

\footnotetext{
${ }^{35}$ Bambirra, Vania. "Los errores de la teoría del foco... Op. Cit. Pág. 40.

${ }^{36} \mathrm{Al}$ respecto, la intelectual manifestó a pie de página: "Esa tendencia de querer recorrer mecánicamente la misma senda de una revolución victoriosa, se verificó también con el movimiento revolucionario europeo, después de la victoria de la revolución rusa, y fue estimulada por los propios bolcheviques, resultando el fracaso de Alemania en 1921 y 1923”. Bambirra, Vania. "Los errores de la teoría del foco... Op. Cit. Pág. 41.

${ }^{37}$ Bambirra, Vania. "Los errores de la teoría del foco... Op. Cit. Pág. 41.
} 
La no consideración de la existencia de una vanguardia revolucionaria como el Movimiento 26 de julio, expresada en una orgánica política y estratégica, junto con la deficiencia en el examen de la realidad latinoamericana realizado por el intelectual francés, fueron las principales críticas que la intelectual planteó a la teoría foquista de Régis Debray. En cuanto a la subordinación de lo político a lo militar, Bambirra sostuvo que la revolución socialista tenía que ser necesariamente insurreccional y que sus estrategias no se limitarían sólo al campo como espacio revolucionario, ni a la guerrilla como accionar. Al respecto cuestionó a Debray cuando planteó que la lucha armada "parece tener razones que la teoría no conoce" ${ }^{, 3}$, planteó que el intelectual francés liquidó el papel de la teoría revolucionaria al someter al proceso revolucionario al voluntarismo. La intelectual hizo una defensa de la teoría revolucionaria y a la importancia de que las organizaciones tuvieran una formación y estructura teórica,

Con esto está tratando de destruir el supuesto básico que "sin teoría revolucionaria no hay movimiento revolucionario". Con esto pretende sustituir el marxismo creador por una teoría de la espontaneidad, que consiste exactamente en lo siguiente: existen factores necesarios y factores decisivos. En último término tiene que haber una escala de prioridades, siendo la prioridad decisiva la lucha que automáticamente (mecánicamente) genera la teoría necesaria. Aparece así la teoría como un complemento necesario en la lucha y se comprende perfectamente que para él la lucha significa el fusil en la mano, y que no se está refiriendo a la lucha política e ideológica, pero ocurre que para un revolucionario marxista la cuestión es totalmente al contrario. Sólo hay lucha revolucionaria: cuando se sabe cómo, contra quién y en qué momento hay que luchar ${ }^{39}$

En definitiva, lo que proponía era una teoría revolucionaria caracterizada por la conformación de fuerzas organizadas relacionadas con el movimiento popular, en espacios como la ciudad y el campo. Bambirra propuso que lo político y lo militar debían contar con un sustento teórico, en este caso el marxismo-leninismo y por las particularidades del continente, principalmente su posición en el capitalismo dependiente, éste debía adquirir una impronta antiimperialista, pues la lucha por el socialismo no sería sólo contra las burguesías nacionales, sino también contra EEUU,

Si se quiere derrotar definitivamente al imperialismo en América Latina, es imprescindible la formación militar. La lucha será dura y prolongada; todos los revolucionarios tienen que estar preparados en todos los sentidos y en la medida en que la lucha se generalice, las funciones militares no serán exclusividad de las fuerzas de represión, o de los revolucionarios, sino de todo el pueblo. Los revolucionarios -por tanto- tienen que preparar para combatir y para enseñar a combatir al pueblo ${ }^{40}$

\footnotetext{
${ }^{38}$ Bambirra, Vania. "Los errores de la teoría del foco... Op. Cit. Pág. 44.

${ }^{39}$ Bambirra, Vania. "Los errores de la teoría del foco... Op. Cit. Pág. 45.

${ }^{40}$ Bambirra, Vania. "Los errores de la teoría del foco... Op. Cit. Pág. 49.
} 
Siguiendo en la misma línea, y entregando argumentos que dan cuenta de la importancia de la conjugación de lo político y lo militar, la intelectual puso como ejemplo los casos de la revolución china y vietnamita en las que no observó una separación entre estos dos ejes. Destacó que los partidos comunistas chino y vietnamita no despreciaron la formación ideológica de sus cuadros, entendiendo la importancia vital de que cada combatiente supiera por qué y para qué estaba luchando ${ }^{41}$. Bajo esta idea, la construcción del imaginario político de la intelectual y su aporte a la producción del pensamiento marxista latinoamericano era que los combatientes se forman en la lucha política, ideológica y armada, resaltando la importancia de la teoría, de los objetivos políticos y el accionar insurreccional.

El escenario de la conformación de la nueva cultura política revolucionaria latinoamericana, que se sustentaba en los trabajos de intelectuales como Vania Bambirra, era de constante tensión en las formas que debían adquirir las organizaciones revolucionarias, así se debatían entre el foco y el partido, a lo que la intelectual propuso, siguiendo el marxismo-leninismo, la necesidad de una organización política que guiara el trabajo político, teórico y estratégico. Para justificar dicha apreciación, recurrió a la experiencia histórica de la sociedad latinoamericana planteando,

Sería oportuno recordarle [a Debray] que en América latina existe una enorme disponibilidad revolucionaria de las masas, y que por tanto estas masas siempre siguieron a caudillos que hablaban un lenguaje populista. Tal vez el mejor ejemplo es el de Janio Quadros, en Brasil, que fue elegido con algunos millones de votos... En verdad, las organizaciones de izquierda más antiguas -especialmente los partidos comunistas- siempre estuvieron a la zaga de las masas, usando a veces un lenguaje más tímido que muchos caudillos populistas. América Latina es un suelo fértil para una acción política revolucionaria ${ }^{42}$

Esta interpretación de la realidad latinoamericana hicieron que el trabajo de la intelectual brasileña y especialmente su crítica a la teoría foquista de Debray se centraran en la idea de que las posibilidades revolucionarias se enriquecían por la experiencia de la clase obrera y del movimiento popular en América Latina, como también por la experiencia china y vietnamita, chocando una vez más con la idea de Debray quien planteaba que la revolución latinoamericana se alejaba de las formas que había adquirido la revolución en Asia. Bambirra en respuesta, consideró que la revolución en nuestro continente debía nutrirse de la experiencia internacional, ya que tanto en Asia como en América Latina el carácter de la lucha, el componente político y social tenían similitudes. Por ello sostuvo que la revolución latinoamericana sería prolongada y violenta, se necesitaría a todo el pueblo para luchar contra las burguesías dependientes y el imperialismo. Establecía que América Latina sería una renovación de todas las formas de lucha anteriores; la guerra sería popular, entendiendo que la lucha armada adquiriría diversas formas combinadas, por ejemplo el uso de la guerrilla, la formación de ejércitos regulares, el sabotaje urbano o movilización de masas, a juicio de la intelectual la gran lección de Vietnam; apostó por una revolución

\footnotetext{
${ }^{41}$ Bambirra, Vania. "Los errores de la teoría del foco... Op. Cit. Pág. 52.
}

${ }^{42}$ Bambirra, Vania. "Los errores de la teoría del foco... Op. Cit. Pág. 55. 
nacional y continental para evitar el aislamiento de un país del resto de América Latina, considerando que la unión evitaría la reacción del imperialismo ${ }^{43}$.

\section{La reinterpretación de la Revolución Cubana}

Bambirra profundizó en la crítica al foquismo, en la importancia del proletariado obrero y campesino en el proceso revolucionario y en la configuración de una organización partidaria en un trabajo que tituló La Revolución Cubana: una reinterpretación, editado por el CESO y presentado en la conmemoración de los 20 años del Asalto al Cuartel Moncada en julio de 1973. Una copia fue enviada a Estados Unidos a la Revista Monthly Review tras el golpe de Estado en Chile y fue publicado en México en 1974.

A más de una década del triunfo revolucionario cubano, la intelectual brasileña analizó este proceso construyendo una reinterpretación que planteaba que el foquismo fue un elemento, entre otros, de la estrategia insurreccional del Movimiento 26 de Julio (M-267) y que la Revolución Cubana fue un proceso que se caracterizó por una combinación de estrategias insurreccionales urbanas y campesinas. Con este trabajo consolidó su crítica al foquismo y entregó una nueva visión respecto de la revolución en la isla. Como señaló Ruy Mauro Marini en el prólogo del libro de la intelectual "Será difícil, en adelante, seguir sosteniendo, respecto al proceso cubano, tesis que menoscaban la importancia de la participación de las masas y de la organización partidaria, como las que se han expresado en los planteamientos foquistas. La autora completa así una labor en que apareció como pionera, desde que, bajo el seudónimo de Cléa Silva, sometió por primera vez en América Latina a una crítica sistemática los puntos de vista defendidos por Régis Debray"44.

Este libro planteó una nueva interpretación sobre el proceso revolucionario, que en el plano intelectual representó la apropiación y difusión de una nueva visión del proceso cubano. De acuerdo con lo que señala Horacio Tarcus, el trabajo de Vania Bambirra puede insertarse en un proceso de recepción intelectual, en el cual en uno de sus momentos existe la apropiación, en donde el intelectual se convierte "eventualmente en un nuevo difusor, o receptor, o incluso productor" 45 . En este punto y con este trabajo, Vania Bambirra aportó una visión teórica y práctica, dando cuenta a través de la praxis cubana y del M-26-7 que la revolución latinoamericana adquiría un carácter marxista-leninista, rompiendo con la visión stalinista, que a juicio de Michael Löwy cumplió un "papel nefasto, colocando a generaciones enteras de militantes comunistas sinceros y dedicados a remolque de la

\footnotetext{
${ }^{43}$ Bambirra, Vania. "Los errores de la teoría del foco... Op. Cit. Pág. 56-57.

${ }^{44}$ Bambirra, Vania. La Revolución Cubana... Op. Cit. Pág. 9-10.

${ }^{45}$ Tarcus, Horacio. Op. Cit. Pág. 18. Sobre la recepción intelectual, Horacio Tarcus sostiene que "remite a un proceso mayor de producción/difusión intelectual donde es necesario discriminar (analíticamente) a productores, difusores, receptores y consumidores de las ideas, aunque estos procesos se confundan en la práctica y estos roles puedan ser asumidos en forma simultánea por un mismo sujeto. Es así que dentro del proceso global de producción y circulación de las ideas, podemos distinguir no etapas temporales sucesivas sino distintos momentos, a cada uno de los cuales corresponden ciertos tipos de intelectuales, esto es, de sujetos específicos que desarrollan capacidades y habilidades concretas. Estos momentos son: (1) el de la producción; (2) el de la difusión; (3) el de la recepción; (4) el de la apropiación” Pág. 14-15.
} 
burguesía en el camino del oportunismo y la defección" "46 En conjunto con los intelectuales que nutrieron el nuevo período en el pensamiento marxista en el continente, la intelectual difundió y propuso a través de un estudio socio-económico e histórico sobre la Revolución Cubana un imaginario político que se impregnó de la experiencia histórica insurreccionalista y la revitalización de un marxismo que pretendía construir un nuevo paradigma para América Latina.

Vania Bambirra en su reinterpretación de la Revolución Cubana sostuvo que el proceso cubano se inició con el asalto al Cuartel Moncada en 1953, por medio de un movimiento insurreccional posicionado en la ciudad y con la clase obrera como base social. Esto se contrapone a lo propuesto por Debray en que el foco guerrillero era el centro del proceso revolucionario cubano. La diferencia radica en que Debray consideró el proceso revolucionario desde la retirada a la sierra y la construcción del ejército popular en 1958, es decir, cuando se desencadenó la guerra de guerrillas, en tanto Bambirra observó la Revolución Cubana desde asalto al Moncada hasta la consolidación del socialismo en Cuba, a mediados del año 1960, por ello consignó una etapa urbana-insurreccionalista y otra campesina-guerrillera, estableciendo que la Revolución Cubana fue un proceso con diversas acciones insurreccionales encabezadas por el M-26-7.

La comprensión del proceso cubano desde 1953 motivó una nueva vertiente en el conocimiento sobre la Revolución Cubana. Bambirra consignó la importancia de la clase obrera, del Partido Socialista Popular (PSP) y del M-26-7 como base social para el proceso revolucionario y experiencia organizativa. Por otra parte, consignó que entre 1959 y 1960 existió una etapa democrática antiimperialista, consignándolo como un período de transición hacia el socialismo. En esta etapa se destruyó el sistema capitalista cubano y permitió la instalación del socialismo a mediados del año 1960. Estas dos apreciaciones para el período en que las publicó entregaron un nuevo escenario sobre la revolución, en que transcurrido más de diez años se sostenía que desde el triunfo, el primero de enero de 1959, el grupo liderado por Fidel Castro había instaurado el socialismo en Cuba.

En términos históricos, la intelectual brasileña consignó que el insurreccionalismo urbano y campesino del pueblo cubano era la acumulación de experiencias históricas que se expresaron en un conjunto de acciones que fueron llevadas a cabo en los diversos procesos de liberación e insurreccionalismo,

Experiencia acumulada de una amplia tradición de luchas del pueblo cubano. La idea del desembarco fue tomada de la guerra de la independencia, de fines del siglo XIX, dirigida y comandada por Martí y Materes; la idea de los levantamientos urbanos, las tomas de los cuartes y de puntos clave de la ciudad se inspiraba en el movimiento insurreccional de los años 30, en la lucha por el derrocamiento de Machado. La idea de la huelga general tenía también raíces en este movimiento. La dictadura de Machado se derrumbará por la presión de una huelga general que, empezando por

\footnotetext{
${ }^{46}$ Löwy, Michael. La Revolución permanente en América Latina. Cuadernos Rojos, 1972. Pág. 1. Este trabajo fue escrito bajo el seudónimo de Carlos Rossi. https://es.scribd.com/doc/126363202/74404286-Rossi-CarlosLowy-Michael-La-Revolucion-Permanente-en-America-Latina
} 
reivindicaciones económicas, se transformó en un golpe mortal al régimen dictatorial $^{47}$

Plantear que la Revolución Cubana fue una experiencia basada en el voluntarismo revolucionario, como lo consignó Debray, es un desconocimiento sobre la historia cubana y de su praxis insurreccional. Una vez más Bambirra al establecer el proceso revolucionario como una acumulación de experiencia insurreccional histórica, criticó al foquismo y planteó la necesidad de que cada organización revolucionaria conozca la historia de la sociedad en la que se inserta y cuáles han sido sus modos de actuar. Por ello, el imaginario político de la intelectual cuenta con la perspectiva histórica al analizar la realidad cubana y la experiencia del movimiento popular.

El estudio que hizo Bambirra en relación a la Revolución Cubana, abrió un nuevo horizonte respecto del "hacer" la revolución. La intelectual planteó que hasta el fracaso de la huelga general de 1958 el M-26-7 tuvo como campo de acción la ciudad y las guerrillas campesinas como su complemento, al contrario de lo que sostuvo Régis Debray. Así el planteamiento foquista que se basaba en la experiencia cubana sólo consideró el movimiento guerrillero desestimando el movimiento insurreccional urbano. Si bien la huelga general de 1958 no tuvo el éxito esperado y fue el punto de inflexión para el desarrollo de la guerrilla rural como principal estrategia, no se debe desconocer la importancia de las ciudades en la primera etapa del proceso,

Demostró también que la destrucción del aparato político militar del régimen dictatorial sería el producto de la combinación de múltiples formas de lucha. Y, finalmente demostró que, por más corrupto que fuera el ejército de Batista, éste no se descompondría de un solo golpe, sino que sería paulatinamente destruido en lo político y en lo militar, en el curso del desarrollo de una nueva estrategia compleja y amplia $^{48}$

Esta es una de las características que destacó la intelectual del proceso cubano y le permitió sostener que en la revolución se combinaron variadas formas de luchas tanto insurreccionalistas como guerrilleras y que estas variaron de acuerdo a las coyunturas, contextos y objetivos políticos. Bambirra apeló a la reconstrucción histórica del proceso revolucionario cubano para dar cuenta de la existencia de una organización partidaria como vanguardia y de las masas populares como actores relevantes de la revolución, para ello planteó dos factores ${ }^{49}$ que argumentan estas afirmaciones: primero, el apoyo popular en la lucha insurreccional que se manifestó a través de los campesinos cubanos a los guerrilleros, cuestión que reflejó la existencia en la zona rural de un ambiente político y segundo, visualizó el trabajo de una organización partidaria como el M-26-7 que se extendió por todo el país creando las condiciones para el desarrollo de la lucha insurreccional y que contaba con los recursos para encabezar el proceso revolucionario que terminó con la dictadura de Batista. En definitiva, la intelectual sostuvo que hasta la huelga general de 1958 la práctica

\footnotetext{
${ }^{47}$ Bambirra, Vania. La Revolución Cubana:... Op. Cit. Pág. 40.

${ }^{48}$ Bambirra, Vania. La Revolución Cubana:... Op. Cit. Pág. 44.

${ }^{49}$ Bambirra, Vania. La Revolución Cubana:... Op. Cit. Pág. 50-51.
} 
política e insurreccional era la lucha urbana, pero a partir de la ofensiva del ejército de Batista la lucha guerrillera se transformó en la ofensiva principal. Por lo tanto, dentro de la estrategia militar-insurreccional del proceso revolucionario, el foco guerrillero fue un tipo de acción que ocuparon los revolucionarios dentro de una compleja gama de acciones urbanas y campesinas. Así, Bambirra planteó que una lucha revolucionaria puede adquirir una diversidad de acciones insurreccionales las que variarían en relación al bando opositor y a las características históricas, sociales y geográficas del país en que se desarrollan, por ello las organizaciones revolucionarias debían contar con una infraestructura política y militar que constantemente evaluara y definiera objetivos políticos y militares como lo hizo el M-26-7.

\section{Conclusiones}

El imaginario político de Vania Bambirra configuró una visión del marxismo latinoamericano que veía en la revolución socialista la salida al capitalismo dependiente y la construcción de un nuevo orden social. Su planteamiento se transformó en una nueva forma de hacer revolución y en una nueva mirada sobre la lucha armada. Su apuesta por el marxismo-leninismo como ruptura ante el reformismo y revisionismo propuesto por la URSS después de la muerte de Stalin, se edificó a partir de su inserción en el contexto político e intelectual latinoamericano, cuyo punto de inflexión fue la Revolución Cubana. Este contexto permitió la instalación de una nueva forma de pensar el marxismo, ahora cubierto por el manto de la praxis revolucionaria, lo que tuvo como consecuencia el surgimiento de una cultura política revolucionaria con una moral militante de entrega y un accionar volcado a la construcción de organizaciones con una estructura política-militar.

La intelectual estudió el insurreccionalismo del movimiento popular y las organizaciones revolucionarias, planteando, en su crítica al foquismo, la necesidad del partido como vanguardia revolucionaria, el proletariado campesino y urbano como base social y la construcción de una estrategia político-militar sin limitar los elementos teóricos que dieran sustento al accionar. Con un análisis social, económico e histórico reinterpretó la Revolución Cubana entregando una nueva visión respecto de la estrategia del Movimiento 26 de julio, la clase obrera y campesinado cubano, profundizando en su crítica a la Teoría del Foco de Régis Debray.

Vania Bambirra planteó que la lucha por el socialismo era una lucha política de liberación de la dependencia capitalista y antiimperialista. Sostuvo que la izquierda revolucionaria debía contar con una infraestructura ideológica, teórica y militar que le permitiera concientizar a sus militantes, atraer a los sujetos populares hacia sus objetivos y una estrategia insurreccional que les permitiera enfrentar la resistencia de la burguesía y del imperialismo. Consignó la urgencia de contar con una izquierda revolucionaria que superara la etapa reformista de los Partidos Comunistas latinoamericanos y pudieran construir vanguardias. Este tipo de organizaciones, disimiles a las organizaciones foquistas, a juicio de la intelectual podrían llevar a adelante la tarea revolucionaria en Latinoamérica, ya que el foquismo estaba condenado al fracaso. Esta aseveración adquirió importancia porque fue desarrollada cuando se masificaba la teoría foquista en las organizaciones revolucionarias por América Latina. 
Como intelectual, Bambirra entendió que su trabajo debía contribuir a reorientar las estrategias de las organizaciones revolucionarias latinoamericanas aportando con el estudio de esta experiencia en una lógica de producción, que en el caso de Vania Bambirra tuvo que ver con el desarrollo de la Teoría de la Dependencia que le permitió analizar la realidad latinoamericana y desde un plano histórico observar el proceso insurreccional cubano.

Los intelectuales fueron actores políticos importantes en el desarrollo de los procesos revolucionarios latinoamericanos y en la definición de los proyectos socialista. El imaginario político de una década en que el marxismo latinoamericano tuvo un nuevo proceso de desarrollo denominado revolucionario impactó profundamente en la construcción de las organizaciones que tomarían el camino insurreccional en la lucha por el socialismo. La constitución de una nueva forma de hacer política, de hacer la revolución, provocaría el renacer de un marxismo-leninismo con carácter latinoamericano, que conformaría una cultura política revolucionaria, equilibrando teoría y praxis revolucionaria. En este sentido, el imaginario político de Vania Bambirra constituyó una constelación de ideas, representaciones y significaciones de los procesos revolucionarios internacionales y continentales que le permitieron realizar un análisis de la realidad latinoamericana a partir de la Teoría de la Dependencia y aportar a la construcción de un nuevo ideario marxista, decantando en una propuesta de estructuración de organizaciones que tuvieran un cuerpo político, ideológico y militar.

Recibido: 28 marzo 2016 Aceptado: 30 mayo 2016

\section{Bibliografía.}

Bambirra, Vania. Diez años de insurrección en América Latina. Tomo I. Ediciones Prensa Latinoamericana S.A. Chile. Santiago, 1971.

-. "Los errores de la teoría del foco: Análisis crítico de la obra de Régis Debray". En: Monthly Review. Selecciones en castellano, Santiago, No .45 , diciembre de 1967.

—. La Revolución Cubana: una reinterpretación. Editorial. Nuestro Tiempo. México DF, 1974.

—. El capitalismo dependiente latinoamericano. Editorial Siglo XXI. México DF, 1974.

Belinsky, Jorge. “Aproximación indirecta: Lo imaginario en la perspectiva de Jacques Le Goff”. En: Belinsky, Jorge. Lo imaginario: un estudio. Editorial Nueva Visión Argentina, Buenos Aires, 2007.

Castoriadis, Cornelius. La institución imaginaria de la sociedad. Vol. 1. Marxismo y teoría revolucionaria. Turquest Editores, Barcelona, 1983.

Debray, Régis. “¿Revolución en la Revolución?” Revista Punto Final. Suplemento a la edición N ${ }^{\circ}$ 25. 2da quincena marzo 1967. 
- $\quad$ "El castrismo: la gran marcha de América Latina". En: Suplemento a la edición $\mathrm{N}^{\circ} 30$ Revista Punto Final. Primera quincena, junio 1967.

Dussel, Enrique. El último Marx (1863-1882) y la liberación latinoamericana: un comentario a la tercera y a la cuarta redacción de "El capital". Editorial Siglo XXI. México D.F., 1990.

Gallardo, Helio. "Revolución”. En: Salas, Ricardo. Et. Al. Pensamiento Crítico Latinoamericano. Conceptos fundamentales. Ediciones Universidad Católica Silva Henríquez. Santiago, 2005.

Laclau, Ernesto. "Populismo y transformación del imaginario político en América Latina". En: Boletín de Estudios Latinoamericanos y del Caribe No. 42 (Junio de 1987). https://www.jstor.org/stable/25675327

Löwy, Michael. El marxismo en América Latina. Editorial Era. México, 1980.

- "La Revolución permanente en América Latina". Cuadernos Rojos, 1972. En: https://es.scribd.com/doc/126363202/74404286-Rossi-Carlos-Lowy-Michael-La-

Revolucion-Permanente-en-America-Latina

Lozoya, Ivette. "Pensar la revolución: pensamiento latinoamericano e intelectuales en el MIR chileno 1965-1973. Propuesta teórica y metodológica para su estudio desde la historia intelectual y la historia de la violencia". Revista Humanidades. No 27 (Enero-Junio 2013). http://revistahumanidades.unab.cl/wp-content/uploads/2013/07/A8.-LOZOYA.pdf

-. "Debates y tensiones en el Chile de la Unidad Popular. ¿La traición de los intelectuales?",

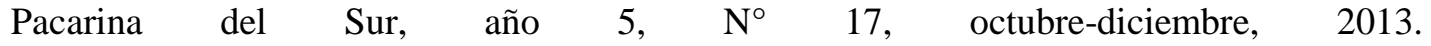
http://www.pacarinadelsur.com/home/oleajes/45-dossiers/dossier-9/812-debates-ytensiones-en-el-chile-de-la-unidad-popular-la-traicion-de-los-intelectuales

Massardo, Jaime. La formación del imaginario político de Luis Emilio Recabarren. Contribución al estudio crítico de la cultura política de las clases subalternas de la sociedad chilena. Editorial LOM. Santiago, 2008.

Plantgean, Evelyn. "La historia de lo imaginario". En: Le Goff. Et. Al. La nueva historia. Editorial Mensajero, Bilbao, 1988.

Tarcus, Horacio. "La historia intelectual y la problemática de la recepción". Introducción del libro Marx en la Argentina. Sus primeros lectores obreros, intelectuales y científicos (1871-1910). Editorial Siglo XXI. Buenos Aires, 2007.http://shial.colmex.mx/textos/Tarcus-6.pdf . 